\title{
Long-Term Effect of Anti-Vegf Agents on Intraocular Pressure in Age-Related Macular Degeneration
}

\author{
João Beato ${ }^{1}$, Ana Catarina Pedrosa ${ }^{1}$, João Pinheiro-Costa ${ }^{1,2}$, Paulo Freitas-da-Costa, \\ Manuel S. Falcão $0^{1,3}$, António Melo', Ângela Carneiro',3, F. Falcão Reis ${ }^{1,3}$ \\ 1Departament of Ophthalmology, São João Hospital Center; \\ 2Departament of Anatomy, Faculty of Medicine of University of Porto; \\ ${ }^{3}$ Departament of Sense Organs, Faculty of Medicine of University of Porto;
}

\begin{abstract}
Aim: To evaluate the effect of intravitreal anti-vascular endothelial growth factor (anti-VEGF) agents on the development of sustained ocular hypertension (OHT) in patients with neovascular age-related macular degeneration (AMD). Methods: A retrospective study of patients with neovascular AMD who received unilateral intravitreal anti-VEGF treatment was performed. Fellow non-injected eyes were used as controls. Initial intraocular pressure (IOP) was measured before the first injection and final IOP was measured 3-4 weeks after the last injection. Eyes that required IOP lowering treatment during follow-up were identified. Results: Seventy-two patients were eligible for the study. Sustained ocular hypertension (OHT) developed in $3(4.2 \%)$ of the injected eyes and in $1(1.4 \%)$ of controls. There was no statistically significant difference between final IOP in the study and control groups. In the study group, patients who received $>20$ anti-VEGF injections showed a significantly larger variation of IOP during follow-up $(p=0.034)$ Conclusion: Eyes receiving a higher number of injections suffer a significantly larger IOP variation than eyes treated with fewer injections, but larger studies are needed to conclude if treatment with intravitreal anti-VEGF agents increases the risk of developing sustained OHT.
\end{abstract}

\section{INTRODUCTION}

Age-related macular degeneration (AMD) is the leading cause of irreversible blindness worldwide in people over 65 of age. The use of intravitreal anti-vascular endothelial growth factor (VEGF) agents for treatment of exudative AMD has drastically changed the visual outcome of these patients. Anti-VEGF therapy is known to have a very good safety profile which makes it suitable for long treatment periods ${ }^{1}$. However, concerns about anti-VEGF effect on intraocular pressure (IOP) have risen in the last few years. It is already known that there is a transient elevation in IOP immediately after any intravitreal injection, which normalizes over minutes to hours ${ }^{2,3}$. Nevertheless, the long-term effect of multiple anti-VEGF injections remains controversial ${ }^{4-6}$. In our study, we aimed to evaluate the effect of intravitreal anti-VEGF agents on the development of sustained OHT in patients with AMD, and to correlate it with factors related to the patient and treatment characteristics.

\section{MATERIAL AND METHODS}

This was a retrospective case-control study of patients with neovascular AMD treated between August 2007 and September 2014 at a tertiary care center, São João Hospital Center, Porto, Portugal. This study respects the principles in Helsinki declaration and was approved by the ethics committee. 
Patients with AMD who received intravitreal anti-VEGF treatment in one eye during the study period and no current or previous intravitreal anti-VEGF treatment in the fellow eye were eligible for the study. The following exclusion criteria were considered: other causes of choroidal neovascularization; history of glaucoma or ocular hypertension before the first anti-VEGF injection; current or previous intra-ocular inflammation; history of photodynamic therapy; local or systemic steroid treatment; previous retina surgery or any ocular surgery (except for glaucoma) during follow-up in either eye. Patients' records were reviewed to collect all relevant information.

Eyes treated with intravitreal anti-VEGF injections were included in the study group and fellow eyes were used as controls. Anti-VEGF therapy could include bevacizumab $(1.25 \mathrm{mg} / 0.05 \mathrm{ml})$, ranibizumab $(0.5 \mathrm{mg} / 0.05 \mathrm{ml})$ or aflibercept $(2 \mathrm{mg} / 0.05 \mathrm{ml})$. Intravitreal injections were performed in the operating room under topical anesthesia using a sharp 30 -gauge needle. After the injection, patients received ofloxacin eye drops 5 times daily for 5 days. No steroids were given. No eye received IOP-lowering medications or anterior chamber paracentesis before or after intravitreal injection. It should be noted that, at our center, the pro re nata dosing regimen is used in the majority of patients.

IOP was measured with Goldmann applanation tonometry. Initial IOP was measured before the first injection and final IOP 3-4 weeks after the last injection. If patients needed IOP lowering therapy, the last IOP measurement without treatment was considered the final IOP. Ocular hypertension was defined as sustained IOP $>21 \mathrm{mmHg}$.

We also evaluated the influence of the following factors on IOP: number of injections $(\leq 10,11-20,>20)$, interval between injections ( $\leq 45,45-90,>90$ days), phakic status of the patient and presence of pseudoexfoliation syndrome (PEX).

Statistical analysis was performed with SPSS 20.0.
Results are presented as mean \pm standard deviation and were considered statistically significant if $\mathrm{p}<0.05$.

\section{RESULTS}

72 patients fulfilled the selection criteria and were included in the analysis. As mentioned previously, treated eyes $(n=72)$ were included in the study group and uninjected fellow eyes $(n=72)$ were used as controls. The mean age of the study population was $76.6 \pm 6.8$ years (range 57-90 years) and 58.3\% were women. The mean follow-up period was $927.4 \pm 646.6$ days. $38.9 \%$ of patients were treated with bevacizumab only, $19.4 \%$ with ranibizumab only and $41.7 \%$ with multiple anti-VEGF agents (bevacizumab, ranibizumab and/or aflibercept). The mean number of injections was $15.6 \pm 12.4$. PEX syndrome was present in $5.4 \%$ of injected eyes and in $4.1 \%$ of controls, and $29.7 \%$ of eyes in both groups were pseudophakic.

Initial and final IOP values in the total sample, the study group and the control group are presented in Table 1. Mean final IOP was higher than mean initial IOP in all groups, but the difference only reached statistical significance in the total sample $(p=0.045)$. Mean initial IOP values were similar in the study and control groups while mean final IOP was slightly higher in the study group, but this difference was not statistically significant $(p=0.42)$.

During follow-up, OHT developed in three of the injected eyes $(4.2 \%)$ and in one of the controls $(1.4 \%)$. The characteristics of these patients are shown in Table 2. In all patients who developed sustained OHT, IOP was controlled with drops, except in one patient who also needed glaucoma surgery. This patient only developed OHT in the injected eye although he had PEX syndrome bilaterally.

Regarding the study group, Table 3 describes the

Table 1 IOP values

\begin{tabular}{|c|c|c|c|c|}
\hline & Total sample (n=144) & Study group $(\mathbf{n}=\mathbf{7 2})$ & Control group (n=72) & Study vs. control group \\
\hline $\begin{array}{c}\text { Initial IOP } \\
(\mathrm{m} \text { man } \pm \text { SD) }\end{array}$ & $14.9 \pm 2.6$ & $14.9 \pm 2.6$ & $14.9 \pm 2.7$ & $\begin{array}{c}\text { Similar initial IOP } \\
(\mathrm{p}=0.97)\end{array}$ \\
\hline $\begin{array}{c}\text { Final IOP } \\
(\mathrm{mean} \pm \mathrm{SD})\end{array}$ & $15.6 \pm 3.5$ & $15.8 \pm 3.8$ & $15.4 \pm 3.1$ & $\begin{array}{c}\text { Slightly higher final IOP } \\
\text { in the study group but } \\
\text { not statistically signifi- } \\
\text { cant }(\mathrm{p}=0.42)\end{array}$ \\
\hline $\begin{array}{c}\text { Final vs. initial } \\
\text { IOP }\end{array}$ & $\begin{array}{c}\text { Final IOP significantly } \\
\text { higher than initial IOP } \\
(\mathrm{p}=0.045)\end{array}$ & $\begin{array}{c}\text { Final IOP higher than } \\
\text { initial IOP but not } \\
\text { statistically significant } \\
(\mathrm{p}=0.07)\end{array}$ & $\begin{array}{c}\text { Final IOP higher than } \\
\text { initial IOP but not } \\
\text { statistically significant } \\
(\mathrm{p}=0.33)\end{array}$ & \\
\hline
\end{tabular}

IOP: intraocular pressure; SD: standard deviation. 
Table 2 | Characteristics of patients who developed sustainned OHT.

\begin{tabular}{|c|c|c|c|c|c|c|c|c|c|}
\hline Patient & Sex & $\begin{array}{l}\text { Age at } 1^{\text {st }} \\
\text { injection }\end{array}$ & $\begin{array}{l}\text { Number of } \\
\text { injections }\end{array}$ & $\begin{array}{l}\text { Interval from } 1^{\text {st }} \\
\text { injection until final } \\
\text { IOP measurement }\end{array}$ & $\begin{array}{c}\text { Inicial } \\
\text { IOP } \\
(\mathrm{mmHg})\end{array}$ & $\begin{array}{c}\text { Final } \\
\text { IOP } \\
(\mathrm{mmHg})\end{array}$ & $\begin{array}{c}\text { IOP } \\
\text { Management }\end{array}$ & Cause & $\begin{array}{c}\text { PEX } \\
\text { Syndrome }\end{array}$ \\
\hline 1 & $\mathrm{~F}$ & 79 & $\begin{array}{c}29 \\
0\end{array}$ & $\begin{array}{l}4 \text { years } \\
6 \text { months }\end{array}$ & $\begin{array}{l}12 \\
12\end{array}$ & $\begin{array}{l}23 \\
19\end{array}$ & $\begin{array}{c}\text { Drops } \\
-\end{array}$ & OHT & - \\
\hline 2 & M & 76 & $\begin{array}{c}12 \\
0\end{array}$ & $\begin{array}{c}1 \text { years } \\
5 \text { months }\end{array}$ & $\begin{array}{l}18 \\
18\end{array}$ & $\begin{array}{l}30 \\
18\end{array}$ & $\begin{array}{c}\text { Drops }+ \text { SLT } \\
-\end{array}$ & OHT & $\begin{array}{l}\text { Yes } \\
\text { Yes }\end{array}$ \\
\hline 3 & M & 70 & $\begin{array}{c}12 \\
0\end{array}$ & $\begin{array}{c}3 \text { years } \\
0 \text { months }\end{array}$ & $\begin{array}{l}18 \\
18\end{array}$ & $\begin{array}{l}24 \\
21\end{array}$ & $\begin{array}{l}\text { Drops } \\
\text { Drops }\end{array}$ & OHT & - \\
\hline 4 & M & 75 & $\begin{array}{l}4 \\
0\end{array}$ & $\begin{array}{c}0 \text { years } \\
10 \text { months }\end{array}$ & $\begin{array}{l}14 \\
14\end{array}$ & $\begin{array}{l}20 \\
22\end{array}$ & $\begin{array}{l}\text { Drops } \\
\text { Drops }\end{array}$ & OHT & $\begin{array}{c}\text { Yes } \\
-\end{array}$ \\
\hline
\end{tabular}

relationship between IOP variation and the number of injections performed. While results were not significant in the subgroups receiving a lower number of injections, we found that IOP significantly increased during follow-up in the group receiving $>20$ injections (mean IOP variation +2.20 with a $95 \%$ CI of +0.10 to +4.30 ). In comparison to those who received $\leq 20$ injections, IOP variation was significantly higher $(\mathrm{p}=0.034)$ in the subgroup receiving more injections. On the other hand, IOP variation did not significantly correlate with the interval between injections or with phakic status.

Table 3 Relationship between IOP variation and number of injections

\begin{tabular}{|c|c|c|}
\hline $\begin{array}{c}\text { Number of } \\
\text { injections }\end{array}$ & $\begin{array}{c}\text { Mean IOP } \\
\text { variation (final- } \\
\text { initial) }\end{array}$ & $\begin{array}{c}\mathbf{9 5 \%} \text { Confidence } \\
\text { interval }\end{array}$ \\
\hline $1-10$ & +0.21 & -0.80 to +1.23 \\
\hline $11-20$ & -0.29 & -3.05 to +2.47 \\
\hline$>20$ & +2.20 & +0.10 to +4.30 \\
\hline
\end{tabular}

IOP: intraocular pressure

\section{DISCUSSION}

In our study, we did not find conclusive evidence that treatment with intravitreal anti-VEGF agents increases the risk of developing sustained OHT. There was no statistically significant difference between final IOP in the study and control groups. We also did not find a statistically significant difference between final and initial IOP in either the study or the control group. On the other hand, we verified that final IOP was significantly higher than initial IOP in the total study population, which is in agreement with the well-known fact that mean IOP increases with age ${ }^{4}$.

Sustained OHT developed in $4.2 \% \quad(n=3)$ of injected eyes, which is consistent with previous reports ${ }^{7-9}$. In contrast, sustained OHT was observed in only $1.4 \%(n=1)$ of fellow non-injected eyes. Despite this apparent difference, the number of eyes that developed this outcome is too small to draw any definitive conclusions.

When we analyzed the results obtained in the study group according to the number of injections received, we verified that IOP variation was significantly larger in patients who received a higher number of injections. This suggests that, after multiple injections, intravitreal anti-VEGF agents may in fact lead to a sustained increase in IOP and even to the development of sustained OHT in a subset of patients. However, these results must be interpreted with caution, as in general patients who received more injections were followed up for a longer period of time and, thus, this correlation may once again be attributable to aging and not to the effect of anti-VEGF agents.

All patients that developed OHT had controlled IOP with medical therapy, except one that also required glaucoma surgery. Previous reports ${ }^{13,14}$ have shown that sustained IOP after repeated intravitreal injections might need surgical procedures besides drops.

Several authors have reported the development of sustained increased IOP in a subset of patients receiving anti-VEGF therapy for neovascular $\mathrm{AMD}^{7-11}$. Pathophysiological mechanisms responsible for this potential adverse effect remain elusive but may include: traumatic trabecular meshwork injury caused by the repeated expansion of the eye's volume after injections, and blockade of aqueous humor outflow via the trabecular meshwork secondary to anti-VEGF biological effects or protein aggregates and contaminant particles ${ }^{6}$. However, none of the studies published until now conclusively establishes a causal relationship between anti-VEGF therapy and a sustained rise in IOP, as these studies are case series or retrospective reviews with a relatively small sample size and many of them lack a proper control group ${ }^{4}$.

In our study, only patients who received intravitreal anti-VEGF treatment in one eye during the study period and 
no current or previous intravitreal anti-VEGF treatment in the fellow eye were eligible. This way, we were able to use non-injected fellow eyes as controls, ensuring an adequately matched control group. On the other hand, it should be noted that non-injected eyes may not be true controls as they may also suffer the effects of the anti-VEGF agent injected in the fellow eye and subsequently absorbed into the systemic circulation $^{12}$. This may have led to an underestimation of the differences between the study and control groups and of the long-term effect of anti-VEGF intravitreal therapy on IOP.

Reviewed patients were followed-up on average for a long period of time. On the other hand, as other studies published until now, ours is also retrospective in nature, and thus it is susceptible to selection bias.

Although eyes receiving $>20$ anti-VEGF injections suffer a significantly larger IOP variation than eyes treated with fewer injections, we did not find conclusive evidence that treatment with intravitreal anti-VEGF agents increases the risk of developing sustained OHT.

In the future, prospective studies with an appropriate control group and a large sample size are needed to further clarify the long-term effect of anti-VEGF therapy on IOP in patients with neovascular AMD. Until then, physicians involved in AMD management should be aware that sustained IOP increase is a possible adverse effect of anti-VEGF agents. If this proves to be true, it seems to be a relatively infrequent effect, but it still may have a serious impact by increasing ocular morbidity in patients already afflicted by AMD.

\section{Acknowledgements}

The authors thank all the orthoptists that collaborate in the Ophthalmology Department.

\section{BIBLIOGRAPHY}

1. Fung AE, Rosenfeld PJ, Reichel E. The International Intravitreal Bevacizumab Safety Survey: using the internet to assess drug safety worldwide. Br J Ophthalmol. 2006;90:1344-1349.

2. Kim JE, Mantravadi AV, Hur EY, et al. Short-term intraocular pressure changes immediately after intravitreal injections of anti-vascular endothelial growth factor agents. Am J Ophthalmol. 2008;146(6):930-4.

3. Lemos-Reis R, Moreira-Gonçalves N, Melo AB, Carneiro AM, Falcão-Reis FM. Immediate effect of intravitreal injection of bevacizumab on intraocular pressure. Clin Ophthalmol. 2014 Jul 23;8:1383-8.

4. Singh RS, Kim JE. Ocular Hypertension Following
Intravitreal Anti-vascular Endothelial Growth Factor Agents. Drugs Aging (2012) 29:949-956

5. Aref AA. Management of immediate and sustained intraocular pressure rise associated with intravitreal antivascular endothelial growth factor injection therapy. Curr Opin Ophthalmol. 2012 Mar;23(2):105-10.

6. SooHoo JR1, Seibold LK, Kahook MY. The link between intravitreal antivascular endothelial growth factor injections and glaucoma. Curr Opin Ophthalmol. 2014 Mar;25(2):127-33.

7. Adelman RA1, Zheng Q, Mayer HR. Persistent ocular hypertension following intravitreal bevacizumab and ranibizumab injections. J Ocul Pharmacol Ther. 2010 Feb;26(1):105-10. doi: 10.1089/jop.2009.0076.

8. Good TJ, Kimura AE, Mandava N, Kahook MY. Sustained elevation of intraocular pressure after intravitreal injections of anti-VEGF agents. Br J Ophthalmol. 2011 Aug;95(8):1111-4.

9. Tseng JJ, Vance SK, Della Torre KE, Mendonca LS, Cooney MJ, Klancnik JM, Sorenson JA, Freund KB. Sustained increased intraocular pressure related to intravitreal antivascular endothelial growth factor therapy for neovascular age-related macular degeneration. J Glaucoma. 2012 Apr-May;21(4):241-7.

10. Hoang QV, Tsuang AJ, Gelman R, et al. Clinical predictors of sustained intraocular pressure elevation due to intravitreal antivascular endothelial growth factor therapy. Retina 2013; 33:179- 187.

11. Mathalone N, Arodi-Golan A, Sar S, Wolfson Y, Shalem M, Lavi I, Geyer O.Sustained elevation of intraocular pressure after intravitreal injections of bevacizumab in eyes with neovascular age-related macular degeneration. Graefes Arch Clin Exp Ophthalmol. 2012 Oct; 250(10):1435-40.

12. Carneiro AM, Costa R, Falcão MS, Barthelmes D, Mendonça LS, Fonseca SL, Gonçalves R, Gonçalves C, Falcão-Reis FM, Soares R. Vascular endothelial growth factor plasma levels before and after treatment of neovascular age-related macular degeneration with bevacizumab or ranibizumab. Acta Ophthalmol. 2012 Feb;90(1):e25-30.

13. Choi DY, Ortube MC, McCannel CA, Sarraf D, Hubschman JP, McCannel TA, Gorin MB. Sustained elevated intraocular pressures after intravitreal injection of bevacizumab, ranibizumab, and pegaptanib. Retina. 2011 Jun;31(6):1028-35.

14. Skalicky SE, Ho I, Agar A, Bank A. Glaucoma filtration surgery following sustained elevation of intraocular pressure secondary to intravitreal anti-VEGF injections. Ophthalmic Surg Lasers Imaging. 2012 Jul 1;43(4):328-34. 